\title{
Research on placebo analgesia is relevant to clinical practice
}

\author{
Charles W Gay ${ }^{1 *}$ and Mark D Bishop ${ }^{2,3}$
}

\begin{abstract}
Over the decades, research into placebo responses has shed light onto several endogenous (i.e. produced from within) mechanisms underlying modulation of pain perception initiated after the administration of inert substances (i.e. placebos). Chiropractors and manual therapists should embrace analgesic-placebo-research in an attempt to maximize clinical benefit. Historical views that placebo responses are fake, passive, undesirable, and require deception and therefore should be minimized and avoided in clinical practice are outdated. Further, statements that contend the placebo response represents a single mechanism are overly simplistic. This commentary will discuss research that shows that there are several active biological processes underlying modulation of pain perception involved in placebo analgesia and its counterpart nocebo hyperalgesia. We contend that it is highly likely that, to some extent, all of these biological processes are engaged, in varying degrees, following all interventions and represent endogenous pain modulating processes. Failure, of chiropractors and manual therapists, to embrace a more contemporary view of analgesic-placebo-research serves as a barrier to transferring knowledge into clinical practice and represents a missed opportunity to improve the delivery of current treatments.
\end{abstract}

Keywords: Placebo, Endogenous pain modulation, Placebo response

\section{Background}

Evidence-based medicine deals with the use of current best evidence in clinical decision-making and other aspects of patient care. The assumption that simply having the evidence available or providing authoritative clinical practice guidelines will result in practice change and improved patient outcomes is incorrect [1,2]. A number of physician behaviors have been identified that act as barriers to translating evidence into clinical practice [3]. Two domains of those barriers are physician's knowledge and attitudes. This commentary addresses knowledge awareness and outdated attitudes surrounding the clinical improvement seen following the administration of a placebo. By addressing these potential barriers chiropractors and manual therapists may be more open to analgesicplacebo-research and its counterpart hyperalgesia-noceboresearch. In turn, clinical practice may be influenced by knowledge gained from this field, applying evidence to

\footnotetext{
*Correspondence: chaz.gay@ufl.edu

'Rehabilitation Science Doctoral Student, University of Florida, Gainesville, Florida, USA

Full list of author information is available at the end of the article
}

decision-making and the context in which interventions are delivered with a goal of improving patient outcomes.

\section{Main text}

Misconceptions about placebo responses continue in the general public and among healthcare professionals $[4,5]$. There has been a push for healthcare professionals to re-think what a placebo response represents and the applicability of knowledge gained from placebo-analgesiaresearch that can be applied ethically in clinical practice [6-12]. Rethinking placebo and nocebo responses as endogenous modulatory mechanisms broadens the focus of care beyond just the intervention to include the context in which interventions are delivered. Historical views that placebo responses represent fake, passive, and undesirable results; require deception; and should be minimized and avoided in clinical practice continue today among healthcare providers. Further, the placebo response has been described as a single mechanism through which an intervention may induce a positive therapeutic outcome [9]. Harboring such views may bias manual therapy practitioners away from valuable clinical evidence that may

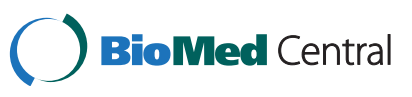


influence their clinical decision making. This commentary presents research that opposes these views.

Changes in the perceived intensity of pain are often attributed to a variety of factors lumped into three board categories: (1) condition related factors, (2) the specific effects of treatment, and/or (3) treatment contextual effects [13]. Condition related factors include the natural course of the condition and regression to the mean. Specific treatment effects are the unique effects associated with the 'active' ingredient of the treatment. Treatment context includes a host of signs, symbols and physician interactions that convey information to the individual. In recent years, researchers have used placebo-analgesia and its negative equivalent, nocebo-hyperalgesia to investigate the neuronal underpinnings of treatment contextual effects. Although, these three categories are practical and useful, they can create a misconception that there are unique biological pathways that do not overlap or interact underlying the categories. This misconception is highlighted by the notion that a predictable estimate of change in pain perception can be determined simply by a treatment's active biological properties.

For example, findings from one study significantly challenge the convention that an active biological agent produces a consistent therapeutic effect within an individual. By convention, researchers acknowledge that the active biological agent in a drug will vary across people, depending on a multitude of personal factors. However, what is not acknowledged so frequently is that within one individual, the therapeutic effect can significantly vary. By experimentally manipulating an individual's expectation through instructional sets, it was shown that the therapeutic effect of the active ingredient of remifentanil, a potent synthetic $\mu$-opioid agonist, can be significantly modulated [14]. The study manipulated subjects' expectations by instructing them that remifentanil is a widely used opioid that relieves pain when infused intravenously, but can worsen pain when the infusion ceases [14]. Hidden administration of the drug produced less perceived pain than baseline, open administration of the drug produced significantly more hypoalgesia than hidden administration and when the drug was continuously administered but the subjects were told it had stopped, the perception of pain retuned to baseline values [14]. The estimated therapeutic effect size of the active ingredient in remifentanil spanned from no effect to a moderate effect, depending on the expectancy created by the instructional set.

Embedded in every pain-relieving treatment are contextual effects. Physician interactions, signs and symbols convey information to the individual with the potential for producing therapeutic and counter-therapeutic responses (ie placebo and nocebo responses respectively) [15]. The estimated therapeutic effect of treatment context following the administration of an inert substance has been shown to be substantial, albeit variable [15-21]. One factor that is not causing the therapeutic effect is the inert substance (ie placebo). Therefore, placeboanalgesia-research provides valuable information about the context in which interventions are delivered. Research into principle mediators of the contextual effects suggest expectancy, desire for a positive outcome and classical conditioning account for a significant portion of the variance in contextual effects [22-24]. Chiropractors and manual therapists should be aware that the context in which they deliver their interventions is as important as the intervention they are giving. Further evidence suggesting the effectiveness of a manual therapy intervention is influenced by patient's expectation comes from a study published by Bialosky et al. [25]. The study showed that by using different instructional sets to positively, negatively and neutrally influence the subjects expectation, the effect of spinal manipulation on a dynamic pain sensitivity measure (temporal summation of second pain) varied [25].

Placebo-analgesia-research has also shown that deception is not integral to inducing a placebo response. One study administered open labeled placebos with patient education that described an active biological pathway for symptom improvement [26]. In this study, the investigators told irritable bowel syndrome (IBS) subjects, that they would be randomized to receive either a placebo sugar pill or no treatment. Subjects receiving the placebo pill were told placebos have been found to produce clinically effective results though a mind-body connection and that by taking the pill, the subjects would be harnessing their own recuperative powers. Greater clinical improvement was found in the placebo group compared to the no-treatment group [26]. Another study examined the repeatability of contextual effects after subjects were told they received an inert substance. In this study, individuals, who received inert pain-relieving cream and experienced pain reductions, were then told they had received a placebo cream. On a subsequent visit those same individuals were again able to experience pain relief a second time using an inert cream [27]. Both of these studies challenge deception's role as a necessary component of the context in which an inert treatment is delivered that produces a positive therapeutic effect.

Finally, placebo-analgesia-research has shed light onto neural mechanisms underlying endogenous pain modulation. Cortical networks involved in processing and modulating the pain experience have been identified and continue to be reinvestigated, redefined and undergo reconceptualization. Activity in these cortical networks influence the perception of pain and modulation can be inhibitory or facilitatory. Research has identified various neurotransmitters including opioids, cannabinoids, dopamines and cholecystokinins, that are used within these 
cortical networks [28-31]. Attributing clinical benefit following the administration of an inert substance to a single mechanism, or terming it a placebo mechanism fails to account for the numerous neural and other biological pathways involved in producing and influencing the perception of pain $[32,33]$.

\section{Conclusion}

Over the decades, research into placebo responses has shed light onto several endogenous (i.e. produced from within) mechanisms underlying modulation of pain perception initiated by the administration of inert substances (i.e. placebos/nocebos). In addition, this growing body of work emphasizes the need for chiropractors' and manual therapists' to be more alert to, and embrace, 'psychologically informed practice'; that is, practice in which recognition of neural mechanisms is equally as important as identification of structural pathology. Chiropractors and manual therapists should embrace analgesic-placeboresearch in an attempt to maximize endogenous pain relieving mechanisms to produce maximum clinical benefit. Historical views that placebo responses are fake, passive, undesirable, and require deception and therefore should be minimized and avoided in clinical practice are outdated. Further, statements that contend the placebo response represents a single mechanism are too simplistic. Instead, in this commentary the authors discussed how several active biological processes underlie analgesicplacebo responses. We contend that it is highly likely that to some extent all of these biological processes, which represent endogenous pain relieving processes, are engaged to various degrees following all interventions that produce a positive clinical outcome.

Failure to embrace a more contemporary view of analgesic-placebo-research may negatively bias chiropractors' and manual therapists' opinions about the potential clinical value of results emerging from this field. These biases serve as a barrier to successfully translating potential benefits for patients into clinical practice in an ethical manner. Analgesic-placebo-research provides insight on how to improve the delivery of current treatments by optimizing clinical benefit and matching the right treatment to the right spinal pain patient at the right time.

\section{Competing interests}

The authors of this manuscript attest there are no conflicts of interest to report.

\section{Authors' contributions}

CWG and MDB contributed equally to the concept, the drafting, and critical revision of the manuscript. All authors read and approved the final manuscript.

\section{Acknowledgements}

This manuscript was written while CWG received support from the University of Florida Alumni Fellowship, NCMIC Foundation and the National Center of Complementary and Alternative Medicine (F32 AT007729-01A1), MDB received support from the National Center of Complementary and Alternative Medicine (R01AT006334).

\section{Author details}

${ }^{1}$ Rehabilitation Science Doctoral Student, University of Florida, Gainesville, Florida, USA. ${ }^{2}$ Associate Professor, Department of Physical Therapy, University of Florida, Gainesville, Florida, USA. ${ }^{3}$ Center for Pain Research \& Behavioral Health, University of Florida, Gainesville, Florida, USA.

Received: 29 August 2013 Accepted: 7 January 2014

Published: 3 February 2014

\section{References}

1. Mafi JN, McCarthy EP, Davis RB, Landon BE: Worsening trends in the management and treatment of back pain. JAMA Intern Med 2013, 173(17):1573-81.

2. National Research Council: Relieving Pain in America: Blueprint for Transofrming Prevention, Care, Education, and Research. Washington, DC: The National Academies Press; 2011.

3. Pierson DJ: Translating evidence into practice. Respiratory care 2009, 54:1386-1401.

4. Bishop FL, Jacobson EE, Shaw JR, Kaptchuk TJ: Scientific tools, fake treatments, or triggers for psychological healing: How clinical trial participants conceptualise placebos. Soc Sci Med 2012, 74(5):767-74.

5. Kisaalita NR, Robinson ME: Analgesic placebo treatment perceptions: acceptability, efficacy, and knowledge. J Pain 2012, 13:891-900.

6. Miller FG, Kaptchuk TJ: The power of context: reconceptualizing the placebo effect. J R Soc Med 2008, 101:222-225.

7. Brody H, Colloca L, Miller FG: The placebo phenomenon: implications for the ethics of shared decision-making. J Gen Intern Med 2012, 27:739-742.

8. Kisaalita NR, Roditi D, Robinson ME: Factors affecting placebo acceptability: deception, outcome, and disease severity. J Pain 2011, 12:920-928.

9. Bialosky JE, Bishop MD, George SZ, Robinson ME: Placebo response to manual therapy: something out of nothing? J Man Manip Ther 2011, 19:11-19.

10. Linde $K$, Fassler $M$, Meissner $K$ : Placebo interventions, placebo effects and clinical practice. Philos Trans R Soc Lond B Biol Sci 2011, 366:1905-1912.

11. Benz LN, Flynn TW: Placebo, nocebo, and expectations: leveraging positive outcomes. J Orthop Sports Phys Ther 2013, 43:439-441.

12. Benedetti F, Amanzio M: Mechanisms of the placebo response. Pulm Pharmacol Ther 2013.

13. Fillingim RB, Price DD: What is controlled for in placebo-controlled trials? Mayo Clin Proc 2005, 80:1119-1121.

14. Bingel U, Wanigasekera V, Wiech K, Ni Mhuircheartaigh R, Lee MC, Ploner M, Tracey I: The effect of treatment expectation on drug efficacy: imaging the analgesic benefit of the opioid remifentanil. Sci Trans/ Med 2011, 3:70ra14.

15. Miller FG, Colloca L: Semiotics and the placebo effect. Perspect Biol Med 2010, 53:509-516.

16. Price DD, Finniss DG, Benedetti F: A comprehensive review of the placebo effect: recent advances and current thought. Annu Rev Psychol 2008, 59:565-590.

17. Hrobjartsson A: The uncontrollable placebo effect. Eur J Clin Pharmacol 1996, 50:345-348.

18. Hrobjartsson A, Gotzsche PC: Is the placebo powerless? An analysis of clinical trials comparing placebo with no treatment. N Engl J Med 2001, 344:1594-1602.

19. Hrobjartsson A, Gotzsche PC: Is the placebo powerless? Update of a systematic review with 52 new randomized trials comparing placebo with no treatment. J Intern Med 2004, 256:91-100.

20. Hrobjartsson A, Gotzsche PC: Unsubstantiated claims of large effects of placebo on pain: serious errors in meta-analysis of placebo analgesia mechanism studies. J Clin Epidemiol 2006, 59:336-338. discussion 339-341.

21. Benedetti F, Carlino E, Pollo A: How Placebos Change the Patient's Brain. Neuropsychopharmacology 2011, 36:339-354.

22. Vase L, Petersen GL, Riley JL 3rd, Price DD: Factors contributing to large analgesic effects in placebo mechanism studies conducted between 2002 and 2007. Pain 2009, 145:36-44.

23. Finniss DG, Kaptchuk TJ, Miller F, Benedetti F: Biological, clinical, and ethical advances of placebo effects. Lancet 2010, 375:686-695. 
24. George SZ, Robinson ME: Dynamic nature of the placebo response. J Orthop Sports Phys Ther 2010, 40:452-454.

25. Bialosky JE, Bishop MD, Robinson ME, Barabas JA, George SZ: The influence of expectation on spinal manipulation induced hypoalgesia: an experimental study in normal subjects. BMC Musculoskelet Disord 2008, 9:19.

26. Kaptchuk TJ, Friedlander E, Kelley JM, Sanchez MN, Kokkotou E, Singer JP, Kowalczykowski M, Miller FG, Kirsch I, Lembo AJ: Placebos without deception: a randomized controlled trial in irritable bowel syndrome. PLoS One 2011, 5:e15591.

27. Chung SK, Price DD, Verne GN, Robinson ME: Revelation of a personal placebo response: its effects on mood, attitudes and future placebo responding. Pain 2007, 132:281-288.

28. Colloca L, Benedetti F: Nocebo hyperalgesia: how anxiety is turned into pain. Curr Opin Anaesthesiol 2007, 20:435-439.

29. Benedetti F: Placebo-induced improvements: how therapeutic rituals affect the patient's brain. J Acupunct Meridian Stud 2012, 5:97-103.

30. Benedetti F, Thoen W, Blanchard C, Vighetti S, Arduino C: Pain as a reward: changing the meaning of pain from negative to positive co-activates opioid and cannabinoid systems. Pain 2013, 154:361-367.

31. Zubieta JK, Stohler CS: Neurobiological mechanisms of placebo responses. Ann N Y Acad Sci 2009, 1156:198-210.

32. Tracey I: Getting the pain you expect: mechanisms of placebo, nocebo and reappraisal effects in humans. Nat Med 2010, 16:1277-1283.

33. Benedetti F: What do you expect from this treatment? Changing our mind about clinical trials. Pain 2007, 128:193-194.

doi:10.1186/2045-709X-22-6

Cite this article as: Gay and Bishop: Research on placebo analgesia is relevant to clinical practice. Chiropractic \& Manual Therapies 2014 22:6.

\section{Submit your next manuscript to BioMed Central and take full advantage of:}

- Convenient online submission

- Thorough peer review

- No space constraints or color figure charges

- Immediate publication on acceptance

- Inclusion in PubMed, CAS, Scopus and Google Scholar

- Research which is freely available for redistribution 